
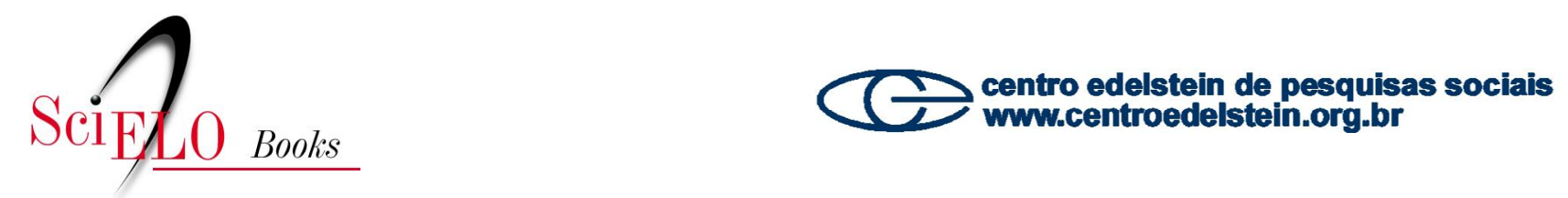

\title{
XIV - Influência sobre o território e a população do interior
}

\author{
Joaquim Nabuco
}

\section{SciELO Books / SciELO Livros / SciELO Libros}

NABUCO, J. Influência sobre o território e a população do interior. In: O abolicionismo [online]. Rio de Janeiro: Centro Edelstein de Pesquisas Sociais, 2011. Influência sobre o território e a população do interior. pp. 96-109. ISBN: 978-85-7982-070-0. https://doi.org/10.7476/9788579820700.0015.

\section{() puburic}

This work is free of known copyright restrictions. http://creativecommons.org/publicdomain/mark/1.0/

Este trabalho está livre de restrições de direito de autor e/ou de direitos conexos conhecidas.

http://creativecommons.org/publicdomain/mark/1.0/

Esta obra está libre de restricciones conocidas de derechos autorales. http://creativecommons.org/publicdomain/mark/1.0/ 


\section{XIV - INFLUÊNCIA SOBRE O TERRITÓRIO E A POPULAÇÃO DO INTERIOR}

Não há um senhor de escravos nesta casa ou fora dela que não saiba perfeitamente bem que se a escravidão ficar fechada dentro de certos limites especificados, a sua existência futura estará condenada. A escravidão não pode encerrar-se dentro de limites certos sem produzir a destruição não só do senhor como também do escravo.

Palavras do juiz Warner, da Geórgia, citadas em The Proposed Slave Empire, de C. S. Mial.

Em 1880 a Assembleia Provincial do Rio de Janeiro dirigiu à Assembleia Geral uma representação em que se lê o seguinte trecho:

É desolador o quadro que se oferece às vistas do viajante que percorre o interior da província, e mais precária é sua posição nos municípios de serra abaixo, onde a fertilidade primitiva do solo já se esgotou e a incúria deixou que os férteis vales se transformassem em lagoas profundas que intoxicam todos aqueles que delas se avizinham. Os infelizes habitantes do campo, sem direção, sem apoio, sem exemplos, não fazem parte da comunhão social, não consomem, não produzem. Apenas tiram da terra alimentação incompleta quando não encontram a caça e a pesca das coutadas e viveiros dos grandes proprietários. Desta arte são considerados uma verdadeira praga, e convém não esquecer que mais grave se tornará a situação quando a esses milhões de párias se adicionar o milhão e meio de escravos, que hoje formam o núcleo das grandes fazendas.

Essas palavras insuspeitas, de uma assembleia escravagista, descrevem a obra da escravidão: onde ela chega queima as florestas, minera e esgota o solo, e quando levanta as suas tendas deixa após de si um país devastado em que consegue vegetar uma população miserável de proletários nômades.

O que se dá no Rio de Janeiro, dá-se em todas as outras províncias onde a escravidão se implantou. André Rebouças, descrevendo o estado atual do Recôncavo da Bahia, esse antigo paraíso do tráfico, fez o quadro da triste condição dos terrenos, ainda os mais férteis, por onde passa aquela praga. Quem vai embarcado a Nazaré, e para em Jaguaripe e Maragojipinho, ou vai pela estrada de ferro a Alagoinhas, e além, vê que a escravidão, ainda mesmo vivificada e alentada pelo vapor e pela locomotiva, é em si um princípio de morte inevitável mais ou menos lenta. Não há à margem do rio, nem da estrada, senão sinais de vida decadente e de atrofia em começo. A indústria grosseira do barro é explorada, em alguns lugares, do modo mais primitivo; em Jaguaripe os edifícios antigos, como a igreja, do período florescente da escravidão, contrastam com a paralisia de hoje.

A verdade é que as vastas regiões exploradas pela escravidão colonial têm um aspecto único de tristeza e abandono: não há nelas o consórcio do homem com a terra, as feições da habitação permanente, os sinais de crescimento natural. $\mathrm{O}$ passado está aí visível, não há porém, prenúncio do futuro: o presente é o definhamento gradual que precede a morte. A população não possui definitivamente o solo: o grande proprietário conquistou-o à natureza com os seus escravos, explorou-o, enriqueceu por ele extenuando-o, depois faliu pelo emprego extravagante que tem quase sempre a fortuna mal adquirida, e, por fim, esse solo voltou à natureza, estragado e exausto.

É assim que nas províncias do Norte a escravidão se liquidou, ou está liquidando, pela ruína de todas as suas antigas empresas. O ouro realizado pelo açúcar foi largamente empregado em escravos, no luxo desordenado da vida senhorial; as propriedades, com a extinção dos vínculos, passaram das antigas famílias da terra, por hipoteca ou pagamento de dívidas, para outras mãos; e os descendentes dos antigos morgados e senhores territoriais achamse hoje reduzidos à mais precária condição imaginável, na Bahia, no Maranhão, no Rio e em Pernambuco, obrigados a recolher-se ao grande asilo das fortunas desbaratadas da escravidão, que é o funcionalismo público. Se, por acaso, o Estado despedisse todos os seus pensionistas e empregados, verse-ia a situação real que a escravidão reduziu os representantes das famílias que a exploraram no século passado e no atual, isto é, como ela liquidou-se, quase sempre pela bancarrota das riquezas que produziu. E o que temos visto é nada em comparação do que havemos de ver.

${ }^{1}$ Garantia de juros, p. 202. 
O Norte todo do Brasil há de recordar, por muito tempo, que o resultado final daquele sistema é a pobreza e a miséria do país. Nem é de admirar que a cultura do solo por uma classe sem interesse algum no trabalho que lhe é extorquido dê esses resultados. Como se sabe, o regime da terra sob a escravidão consiste na divisão de todo o solo explorado em certo número de grades propriedades. ${ }^{2}$ Esses feudos são logo isolados de qualquer comunicação com o mundo exterior; mesmo os agentes do pequeno comércio, que neles penetram, são suspeitos ao senhor, e os escravos que nascem e morrem dentro dos horizontes do engenho ou da fazenda são praticamente galés. A divisão de uma vasta província em verdadeiras colônias penais, refratárias ao progresso, pequenos ashantis em que impera uma só vontade, entregue, às vezes, a administradores saídos da própria classe dos escravos, e sempre a feitores, que em geral são escravos sem entranhas, não pode trazer benefício permanente à região parcelada, nem à população livre que nela mora, por favor dos donos da terra, em estado de contínua dependência.

Por isso também, os progressos do interior são nulos em trezentos anos de vida nacional. As cidades, a que a presença dos governos provinciais não dá uma animação artificial, são por assim dizer mortas. Quase todas são decadentes. A capital centraliza todos os fornecimentos para o interior; é com o correspondente do Recife, da Bahia ou do Rio, que o senhor de engenho e o fazendeiro se entendem, e, assim, o comércio dos outros municípios da província é nenhum. $O$ que se dá na Bahia e em Pernambuco, dá-se em toda a parte, A vida provincial está concentrada nas capitais, e a existência que essas levam, o pouco progresso que fazem, o lento crescimento que têm, mostram que essa centralização, longe de derramar vida pela província, fá-la definhar. Essa falta de centros locais é tão grande que o mapa de cada província poderia ser feito sem se esconder nenhuma cidade, notando-se apenas as capitais. Muitas destas constam mesmo de insignificantes coleções de casas, cujo material todo, e tudo o

\footnotetext{
2 "O antigo e vicioso sistema de sesmarias e do direito de posse produziu o fenômeno de achar-se ocupado quase todo o solo por uma população relativamente insignificante, que não o cultiva e nem consente que seja cultivado. O imposto territorial é o remédio que a comissão encontra para evitar esse mal, ou antes abuso, que criou uma classe proletária no meio de tanta riqueza desaproveitada". Essa classe proletária é a grande maioria da nação. Parecer de uma comissão nomeada em 1874 para estudar o estado da lavoura na Bahia, assinado em primeiro lugar pelo Barão de Cotegipe.
}

que nelas se contém, não bastaria para formar uma cidade norte-americana de décima ordem. A vida nas outras é precária, falta tudo o que é bem estar; não há água encanada nem iluminação a gás, a municipalidade não tem a renda de um particular medianamente abastado, não se encontra o rudimento, o esboço sequer, dos órgãos funcionais de uma cidade. São esses os grandes resultados da escravidão em trezentos anos.

Ao lado dessa velhice antecipada de povoações, que nunca chegaram a desenvolver-se, e muitas das quais hão de morrer sem passar do que são hoje, imagine-se a improvisação de uma cidade americana do Far West, ou o crescimento rápido dos estabelecimentos da Austrália. Em poucos anos nos Estados Unidos uma povoação cresce, passa pelos sucessivos estados, levanta-se sobre uma planta na qual foram antes marcados os locais de edifícios necessários à vida moral da comunhão, e quando chega a ser uma cidade é um todo cujas diversas partes desenvolveram-se harmonicamente.

Mas essas cidades são o centro de uma pequena zona que se desenvolveu, também, de modo radicalmente diverso da nossa zona agrícola. Fazendas ou engenhos isolados, com uma fábrica de escravos, com os moradores das terras na posição de agregados do estabelecimento, de camaradas ou capangas; onde os proprietários não permitem relações entre o seu povo e estranhos; divididos, muitas vezes, entre si por questões de demarcações de terras, tão fatais num país onde a justiça não tem meios contra os potentados; não podem dar lugar à aparição de cidades internas, autônomas, que vivifiquem com os seus capitais e recursos a zona onde se estabeleçam. Tome-se o Cabo, ou Valença, ou qualquer outra cidade do interior de qualquer província, e há de ver-se que não tem vida própria, que não preenche função alguma definitiva na economia social. Uma ou outra que apresenta, como Campinas ou Campos, uma aparência de florescimento, é porque está na fase do brilho meteórico que as outras também tiveram, e da qual a olho desarmado pode reconhecer-se o caráter transitório.

O que se observa no Norte, observa-se no Sul, e observar-se-ia melhor ainda se o café fosse destronado pela Hemilea vastatrix. Enquanto durou a idade do ouro do açúcar, o Norte apresentava um espetáculo que iludia a muitos. As casas, os chamados palacetes, da aristocracia territorial na Bahia e no Recife, as librés dos lacaios, as liteiras, as cadeirinhas, e as carruagens nobres marcaram o monopólio florescente da cana - quando a beterraba ainda não havia aparecido no horizonte. Assim também as riquezas da lavoura do 
Sul, de fato muito exageradas, de liquidação difícil, mas apesar de tudo consideráveis, e algumas, para o país, enormes, representa a prosperidade temporária do café. A concorrência há de surgir, como surgiu para o açúcar, É certo que este pode ser extraído de diversas plantas, ao passo que o café só é produzido pelo cafezeiro; mas diversos países o estão cultivando e hão de produzi-lo mais barato, sobretudo pelo custo do transporte, além de que o Ceilão já mostrou os pés de barro dessa lavoura única.

Quando passar o reinado do café, e os preços baixos já serviram de prenúncio, o Sul há de ver-se reduzido ao estado do Norte. Ponhamos São Paulo e o extremo sul de lado, e consideremos Rio de Janeiro e Minas Gerais. Sem o café, uma e outra são duas províncias decrépitas. Ouro Preto não representa hoje na vida nacional maior papel do que representou Vila Rica nos dias em que a casa de Tiradentes foi arrasada por sentença; Mariana, São João del Rei, Barbacena, Sabará, Diamantina ou estão decadentes, ou, apenas, conseguem não decair. É nos municípios do café que está a parte opulenta de Minas Gerais.

Com São Paulo dá-se um fenômeno particular, Apesar de ser São Paulo o baluarte atual da escravidão, em São Paulo e nas províncias do Sul ela não causou tão grandes estragos; é certo que São Paulo empregou grande parte do seu capital na compra de escravos do Norte, mas a lavoura não depende tanto quanto a do Rio de Janeiro e a de Minas Gerais da escravidão para ser reputada solvável.

Tem-se exagerado muito a iniciativa paulista nos últimos anos, por haver a província feito estrada de ferro sem socorro do Estado, depois que viu os resultados da estrada de ferro de Santos à Jundiaí; mas, se os paulistas não são, como foram chamados, os ianques do Brasil, o qual não tem ianques - nem São Paulo é a província mais adiantada, nem a mais americana, nem a mais liberal de espírito do país; será a Louisiana do Brasil, não o Massachusets - não é menos certo que a província, por ter entrado no seu período florescente no fim do domínio da escravidão, há de revelar na crise maior elasticidade do que as suas vizinhas.

No Paraná, em Santa Catarina, no Rio Grande, a emigração europeia infunde sangue novo nas veias do povo, reage contra a escravidão constitucional, ao passo que a virgindade das terras e a suavidade do clima abrem ao trabalho livre horizontes maiores do que teve o escravo. No vale do
Amazonas, igualmente, a posse da escravidão sobre o território foi até hoje algo nominal; a pequena população formou-se diversamente, longe de senzalas; a navegação a vapor do grande mediterrâneo brasileiro só começou há trinta anos, e a imensa bacia do Amazonas, cujos tributários são como o Madeira, o Tocantins, o Purus, o Tapajós, o Xingu, o Juruá, o Javari, o Tefé, o Japurá, o rio Negro, cursos de água de mais de mil, dois mil e mesmo três mil quilômetros, está assim ainda por explorar, em grande parte em poder dos indígenas, perdida para a indústria, para o trabalho, para a civilização. $\mathrm{O}$ atraso dessa vastíssima área pode ser imaginada pela descrição que faz dela o Sr. Couto de Magalhães, o explorador do Araguaia, no seu livro $O$ selvagem. É um território, conta-nos ele, ou coberto de florestas alagadas, nas quais se navega em canoas como nos pantanais do Paraguai, ou de campinas abertas e despovoadas com algum arvoredo rarefeito.

Os três milhões de quilômetros quadrados de duas das províncias em que se divide a bacia do Amazonas, o Pará e o Amazonas, com espaço para quase seis países como a França, e com o território vazio limítrofe para toda a Europa menos a Rússia, não tem uma população de quinhentos mil habitantes. O estado dessa região é tal que em 1878 o governo brasileiro fez concessão por vinte anos do vale do alto Xingu, um tributário do Amazonas cujo curso é calculado em cerca de dois mil quilômetros, com todas as suas produções e tudo o que nele se achasse, a alguns negociantes do Pará! O Parlamento não ratificou essa doação; mas o fato de ter sido ela feita mostra como, praticamente, ainda é res nullius a bacia do Amazonas. Os seringais, apesar da sua imensa extensão, têm sido grandemente destruídos, e essa riqueza natural do grande vale está ameaçada de desaparecer, porque o caráter da indústria extrativa é tão ganancioso, e por isso esterilizador, no regime da escravidão como o da cultura do solo. O regatão é o agente da destruição no Amazonas como o senhor de escravos o foi no Norte e no Sul.

Por toda a parte - dizia no seu relatório à Assembleia Provincial do Pará em 1862 o presidente Brusque ${ }^{3}$ - onde penetra o homem civilizado nas margens dos rios inabitados, ali encontra os traços não apagados dessa população [os indígenas] que vagueia sem futuro. E a pobre aldeia, às mais das vezes por eles mesmos erguidas em escolhida paragem, onde a terra lhes oferece a mais ampla colheita da pouca mandioca que plantam, desaparece de todo, pouco tempo

\footnotetext{
${ }^{3}$ Comissão do Madeira, pelo cônego F. Bernardino de Souza, p. 139.
} 
depois da sua lisonjeira fundação. O regatão, formidável cancro que corrói as artérias naturais do comércio lícito das povoações centrais, desviando delas a concorrência dos incautos consumidores, não contente com os fabulosos lucros que assim aufere, transpõe, audaz, enormes distâncias e lá penetra também na choça do índio. Então, a aldeia se converte para logo num bando de servidores, que distribui a seu talante, mais pelo rigor do que pela brandura, nos diversos serviços que empreendem na colheita dos produtos naturais. Pelo abandono da aldeia, se perde a roça, a choça desaparece, e o mísero índio em recompensa de tantos sacrifícios e trabalhos, recebe muitas vezes uma calça e uma camisa.

Esses regatões, de quem disse o bispo do Pará, ${ }^{4}$ que "embriagam os chefes das casas para mais facilmente desonrar-lhes as famílias", que "não há imoralidade que não pratiquem", não são mais do que o produto da escravidão, estabelecida nas capitais, atuando sobre o espírito cupido e aventureiro de homens sem educação moral.

Como a aparência de riqueza, que a extração da borracha dá ao vale do Amazonas, foi a do açúcar e do café cultivado pelos processos e com o espírito da escravidão. O progresso e crescimento da capital contrasta com a decadência do interior. É o mesmo em toda a parte. Com a escravidão não há centros locais, vida de distrito, espírito municipal; as paróquias não tiram benefícios da vizinhança de potentados ricos; a aristocracia que possui a terra não se entrega a ela, não trata de torná-la a morada permanente, saudável, e cheia de conforto de uma população feliz; as famílias são todas nômades enquanto gravitam para o mesmo centro, que é a Corte. A fazenda ou o engenho serve para cavar o dinheiro que se vai gastar na cidade, para a hibernação, e o aborrecimento de uma parte do ano. A terra não é fertilizada pelas economias do pobre, nem pela generosidade do rico; a pequena propriedade não existe senão por tolerância, ${ }^{5}$ não há as classes médias que

\footnotetext{
${ }^{4}$ Comissão do Madeira, p. 132.
}

5 "Em regra o fazendeiro enxerga no colono ou agregado, a quem cede ou vende alguns palmos e terreno, um princípio de antagonismo, um inimigo que trabalha por lhe usurpar a propriedade; que lhe prepara e tece rixas e litígios; que lhe seduz os escravos para fugir, roubar-lhe os gêneros de fazenda e vendê-los, a resto de barato, à taberna do mesmo exagregado estabelecido, que assim se locupleta com a jactura alheia. O resultado disso é que o trabalhador, perdendo a esperança de se tornar proprietário, não se sujeita a lavrar os campos da fazenda, nem a lhe preparar os produtos". Parecer das comissões de Fazenda e especial da Câmara dos Deputados sobre a criação do crédito territorial. (1875) p. 21. fazem a força das nações. Há o opulento senhor de escravos, e proletários. A nação, de fato, é formada de proletários, porque os descendentes dos senhores logo chegam a sê-lo.

É um triste espetáculo essa luta do homem com o território por meio do trabalho escravo. Em parte alguma o solo adquire vida; os edifícios que nele se levantam são uma forma de luxo passageiro e extravagante, destinada a pronta decadência e abandono. A população vive em choças onde o vento e a chuva penetram, sem soalho nem vidraças, sem móveis nem conforto algum, com a rede do índio ou o estrado do negro por leito, a vasilha de água e a panela por utensílios, e a viola suspensa ao lado da imagem. Isso é no campo; nas pequenas cidades e vilas do interior, as habitações dos pobres, dos que não têm empregos nem negócio, são pouco mais que essas miseráveis palhoças do agregado ou do morador. Nas capitais de ruas elegantes e subúrbios aristocráticos, estende-se, como nos Afogados de Recife, às portas da cidade, o bairro da pobreza com sua linha de cabanas que parecem, no século XIX, residências de animais, como nas calçadas mais frequentadas da Bahia, e nas praças do Rio, ao lado da velha casa nobre, que fora de algum antigo morgado, ou de algum traficante enobrecido, vê-se o miserável e esquálido antro do africano, como a sombra grotesca dessa riqueza efêmera e do abismo que a atrai.

Quem vê os caminhos de ferro que temos construído, a imensa produção de café que exportamos, o progresso material que temos feito, pensa que os resultados da escravidão não são assim tão funestos ao território. É preciso, porém, lembrar que a aparência atual de riqueza e prosperidade provém de um produto só - quando a população do país excede dez milhões - e que a liquidação forçada desse produto seria nada menos do que uma catástrofe financeira. A escravidão está no Sul no apogeu, no seu grande período industrial, quando tem terras virgens, como as de São Paulo a explorar, e um gênero de exportação precioso a produzir. A empresa, neste momento, porque ela não é outra coisa, está dando algum lucro aos associados. Lucro, de que partilham todas as classes intermédias do comércio, comissários, ensacadores, exportadores; cujas migalhas sustentam uma clientela enorme de todas as profissões, desde o camarada que faz o serviço de votante, até ao médico, ao advogado, ao vigário, ao juiz de paz; e do qual por fim uma parte, e não pequena, é absorvida pelo tesouro para manutenção da cauda colossal do nosso orçamento - o 
funcionalismo público. Com essa porcentagem dos proventos da escravidão, o Estado concede garantia de juros de sete por cento a companhias inglesas que constroem estradas de ferro no país, e assim o capital estrangeiro, atraído pelos altos juros e pelo crédito intato de uma nação que parece solvável, vai tentar fortuna em empresas como a Estrada de Ferro de São Paulo, que têm a dupla garantia do Brasil e do Café.

Mas essa ilusão toda de riqueza, de desenvolvimento nacional, criada por este, como a do açúcar e a do algodão no Norte, como a da borracha no vale do Amazonas, como a do ouro em Minas Gerais, não engana a quem a estuda e observa nos seus contrastes, na sombra que ela projeta. A realidade é um povo antes escravo do que senhor do vasto território que ocupa; a cujos olhos o trabalho foi sistematicamente aviltado; ao qual se ensinou que a nobreza está em fazer trabalhar; afastado da escola; indiferente a todos os sentimentos, instintos, paixões e necessidades, que formam nos habitantes de um mesmo país, mais do que uma simples sociedade - uma nação. Quando o Sr. Silveira Martins disse ao Senado: "O Brasil é o café, e o café é o negro" - não querendo por certo dizer o escravo - definiu o Brasil como fazenda, como empresa comercial de uma pequena minoria de interessados, em suma, o Brasil da escravidão atual. Mas basta que um país, muito mais vasto do que a Rússia da Europa, quase o dobro da Europa sem a Rússia, mais de um terço do Império britânico nas cinco partes do mundo, povoado por mais de dez milhões de habitantes, possa ser descrito daquela forma, para se avaliar o que a escravidão fez dele.

Esse terrível azorrague não açoitou somente as costas do homem negro, macerou as carnes de um povo todo. Pela ação de leis sociais poderosas, que decorrem da moralidade humana, essa fábrica de espoliação não podia realizar bem algum, e foi, com efeito, um flagelo que imprimiu na face da sociedade e da terra todos os sinais da decadência prematura. A fortuna passou das mãos dos que a fundaram às dos credores; poucos são os netos de agricultores que se conservam à frente das propriedades que seus pais herdaram; o adágio "pai rico, filho nobre, neto pobre" expressa a longa experiência popular dos hábitos da escravidão, que dissiparam todas as riquezas, não raro no exterior e, como temos visto, em grande parte, eliminaram da reserva nacional o capital acumulado naquele regime.

A escravidão explorou parte do território estragando-o, e não foi além, não o abarcou todo, porque não tem iniciativa para migrar, e só avidez para estender-se. Por isso, o Brasil é ainda o maior pedaço e terra incógnita no mapa do globo.

Num estado de escravos - diz o Sr. T. R. Cobb, da Geórgia ${ }^{6}-$ a maior prova de riqueza no agricultor é o número dos escravos. A melhor propriedade a deixar aos filhos, e da qual se separam com maior relutância, são os escravos. Por isso, o agricultor emprega o excesso de sua renda em escravos. O resultado natural é que as terras são uma consideração secundária. Não fica saldo para melhorá-las. $\mathrm{O}$ estabelecimento tem valor somente enquanto as terras adjacentes são proveitosas para o cultivo. Não tendo o agricultor afeições locais, os filhos não as herdam. Pelo contrário, ele mesmo os anima a irem em busca de novas terras. O resultado é que, como classe, nunca estão estabelecidos. Essa população é quase nômade. É inútil procurar excitar emoções patrióticas em favor da terra do nascimento, quando o interesse próprio fala tão alto. Por outro lado, onde a escravidão não existe, e os lucros do agricultor não podem ser empregados em trabalhadores, são aplicados em melhorar ou estender a sua propriedade e aformosear o seu solar.

Foi isso o que aconteceu entre nós, sendo que em parte alguma a cultura do solo foi mais destruidora. A última seca do Ceará pôs, de modo mais calamitoso, em evidência uma das maldições que sempre acompanharam, quando não precederam, a marcha da escravidão, isto é, a destruição das florestas pela queimada.

O machado e o fogo são os cruéis instrumentos, escreve o senador Pompeu, com que uma população, ignara dos princípios rudimentares da economia rural, e herdeira dos hábitos dos aborígenes, há dois séculos desnuda sem cessar as nossa serras e vales dessas florestas virgens, só para aproveitar-se o adubo de um roçado em um ano.

A cada passo encontramos e sentimos os vestígios desse sistema, que reduz um belo país tropical da mais exuberante natureza ao aspecto das regiões onde já se esgotou a força criadora da terra.

Para resumir-se, num campo de observação que exigiria um livro à parte, a influência da escravidão, sobre o território e a população que vive dele, foi em todos os sentidos desastrosa. Como exploração do país, os

\footnotetext{
${ }^{6}$ Citado em England, the United States, the Southern Confederacy, by F. W. Sargent, 110.

${ }^{7}$ Memórias sobre o clima e as secas do Ceará, pelo senador Pompeu, p. 42.
} 
seus resultados são visíveis na carta geográfica do Brasil, na qual os pontos negros do seu domínio são uma área insignificante comparada à área desconhecida ou despovoada; como posse do solo explorado, nós vimos o que ela foi e é. O caráter da sua cultura é a improvidência, a rotina, a indiferença pela máquina, o mais completo desprezo pelos interesses do futuro, a ambição de tirar o maior lucro imediato com o menor trabalho próprio possível, qualquer que seja o prejuízo das gerações seguintes. O parcelamento feudal do solo que ela instituiu, junto ao monopólio do trabalho que possui, impede a formação de núcleos de população industrial, e a extensão do comércio no interior. Em todos os sentidos foi ela, e é, um obstáculo ao desenvolvimento material dos municípios; explorou a terra sem atenção à localidade, sem reconhecer deveres para com o povo de fora das suas porteiras, queimou, plantou e abandonou; consumiu os lucros na compra de escravos e no luxo da cidade; não edificou escolas, nem igrejas, não construiu pontes, nem melhorou rios, não canalizou a água nem fundou asilos, não fez estradas, não construiu casas, sequer para os seus escravos, não fomentou nenhuma indústria, não deu valor venal à terra, não fez benfeitorias, não granjeou o solo, não empregou máquinas, não concorreu para progresso algum da zona circunvizinha. $\mathrm{O}$ que fez foi esterilizar o solo pela sua cultura extenuativa, embrutecer os escravos, impedir o desenvolvimento dos municípios, e espalhar em torno dos feudos senhoriais o aspecto das regiões miasmáticas, ou devastadas pelas instituições que suportou, aspecto que o homem livre instintivamente reconhece. Sobre a população toda do nosso interior, ou às orlas das capitais ou nos páramos do sertão, os seus efeitos foram: dependência, miséria, ignorância, sujeição ao arbítrio dos potentados - para os quais o recrutamento foi o principal meio de ação; a falta de um canto de terra que o pobre pudesse chamar seu, ainda que por certo prazo, e cultivar como próprio; de uma casa que fosse para ele o asilo inviolável e da qual não o mandassem esbulhar à vontade; da família - respeitada e protegida. Por último, essa população foi por mais de três séculos acostumada a considerar o trabalho do campo como próprio de escravos; Saída quase toda das senzalas, ela julga aumentar a distância que a separa daqueles, não fazendo livremente o que eles fazem forçados.

Mais de uma vez, tenho ouvido referir que se oferecera dinheiro a um dos nossos sertanejos por um serviço leve e que esse recusara prestá- lo. Isso não me admira. Não se lhe oferecia um salário certo. Se lhe propusessem um meio de vida permanente, que melhorasse a sua condição, ele teria provavelmente aceito a oferta. Mas, quando não a aceitasse, admitindo-se que os indivíduos com quem se verificaram tais fatos represente uma classe de brasileiros que se conta por milhões, como muitos pretendem, a dos que se recusam a trabalhar por salário, que melhor prova da terrível influência da escravidão? Durante séculos ela não consentiu mercado de trabalho, e não se serviu senão de escravos; o trabalhador livre não tinha lugar na sociedade, sendo um nômade, um mendigo, e por isso em parte nenhuma achava ocupação fixa; não tinha em torno de si o incentivo que desperta no homem pobre a vista do bemestar adquirido por meio do trabalho por indivíduos da sua classe, saídos das mesmas camadas que ele. E como vivem, como se nutrem, esses milhões de homens, porque são milhões que se acham nessa condição intermédia, que não é o escravo, mas também não é o cidadão; cujo único contingente para o sustento da comunhão, que aliás nenhuma proteção lhes garante, foi sempre o do sangue, porque essa era a massa recrutável, os feudos agrícolas roubando ao exército os senhores e suas famílias, os escravos, os agregados, os moradores e os brancos?

As habitações já as vimos. São quatro paredes, separadas no interior por uma divisão em dois ou três cubículos infectos, baixas e esburacadas, abertas à chuva e ao vento, pouco mais do que o curral, menos do que a estrebaria. É nesses ranchos que vivem as famílias de cidadãos brasileiros! A alimentação corresponde à independência de hábitos sedentários causada pelas moradas. É a farinha de mandioca que forma a base da alimentação, na qual entra, como artigo de luxo, o bacalhau da Noruega ou o charque do Rio da Prata.

Eles vivem diretamente - diz o Sr. Milet, referindo-se à população, que está "fora do movimento geral das trocas internacionais", avaliada por ele na quinta parte da população do Brasil, e que faz parte desses milhões de párias livres da escravidão - da caça e da pesca, dos frutos imediatos do seu trabalho agrícola, da criação do gado e dos produtos de uma indústria rudimentar. ${ }^{8}$

Foi essa população que se foi internando, vivendo como ciganos, aderindo às terras das fazendas ou dos engenhos onde achava agasalho,

\footnotetext{
${ }^{8}$ Miscelânea econômica, p. 36 .
} 
formando-se em pequenos núcleos nos interstícios das propriedades agrícolas, edificando as suas quatro paredes de barro onde se lhe dava permissão para fazê-lo, mediante condições de vassalagem que constituíam os moradores em servos da gleba.

Para qualquer lado que se olhe, esses efeitos foram os mesmos. Latifundia perdidere Italiam, é uma frase que soa como verdade tangível aos ouvidos do brasileiro. Compare por um momento, quem viajou nos Estados Unidos ou na Suíça, o aspecto do país, da cultura, da ocupação do solo pelo homem. Diz-se que o Brasil é um país novo; sim, é um país novo em algumas partes; virgem mesmo, mas em outras é um país velho; há mais de trezentos anos que as terras foram primeiras desbastadas, as florestas abatidas, e plantados os canaviais. Tome-se Pernambuco, por exemplo, onde no século XVI João Paes Barreto fundou o morgado do Cabo; que tinha no século XVII durante a ocupação holandesa bom número de engenhos de açúcar; que lutou palmo a palmo contra a Companhia das Índias Ocidentais para seguir a sorte de Portugal e compare-se essa província heroica de mais de trezentos anos com países, por assim dizer, de ontem, como as colônias da Austrália e a Nova Zelândia; com os últimos estados que entraram para a União Americana. Se não fora a escravidão, o nosso crescimento por certo não seria tão rápido como os dos países ocupados pela raça inglesa; Portugal não poderia vivificar-nos, desenvolver-nos com os seus capitais, como faz a Inglaterra com as suas colônias; o valor do homem seria sempre menor, e portanto o do povo e o do Estado. Mas, por outro lado, sem a escravidão não teríamos hoje em existência um povo criado fora da esfera da civilização, e que herdou grande parte das suas tendências, por causa das privações que lhe foram impostas e do regime brutal a que o sujeitaram, da raça mais atrasada e primitiva, corrigindo assim, felizmente, a hereditariedade da outra, é certo mais adiantada, porém cruel, desumana, ávida de lucros ilícitos, carregada de crimes atrozes: aquela que responde pelos milhões de vítimas de três séculos escravatura.

Onde quer que se estude, a escravidão passou sobre o território e os povos que acolheram como um sopro de destruição. Ou se a veja nos ergástulos da antiga Itália, nas aldeias da Rússia, nas plantações dos Estados do Sul, ou nos engenhos e fazendas do Brasil, ela é sempre a ruína, a intoxicação e a morte. Durante um certo período ela consegue esconder, pelo intenso brilho metálico do seu pequeno núcleo, a escuridão que o cerca por todos os lados; mas, quando esse pequeno período de combustão acaba, vê-se que a parte luminosa era um ponto insignificante comparado à massa opaca, deserta e sem vida do sistema todo. Dir-se-ia que, assim como a matéria não faz senão transformar-se, os sofrimentos, as maldições, as interrogações mudas a Deus, do escravo, condenado ao nascer a galés perpétuas, criança desfigurada pela ambição do dinheiro, não se extinguem de todo com ele, mas espalham nesse vale de lágrimas da escravidão, em que ele viveu, um fluído pesado, fatal ao homem e à natureza.

É uma terrível pintura - diz o grande historiador alemão de Roma essa pintura da Itália sob o governo da oligarquia. Não havia nada que conciliasse ou amortecesse o fatal contraste entre o mundo dos mendigos e o mundo dos ricos. A riqueza e a miséria ligadas estreitamente uma com a outra expulsaram os italianos da Itália, e encheram a península em parte com enxames de escravos, em parte com silêncio sepulcral. É uma terrível pintura, não, porém, uma que seja particular à Itália; em toda a parte onde o governo dos capitalistas, num país de escravos, se desenvolveu completamente, devastou o belo mundo de Deus da mesma forma. A Itália ciceroniana, como a Hélade de Políbio, como a Cartago de Aníbal. Todos os grandes crimes, de que o capital é culpado para com a nação e a civilização no mundo moderno, ficam sempre tão abaixo das abominações dos antigos, Estados capitalistas, como o homem livre, por mais pobre que seja, fica superior ao escravo, e só quando a semente de dragão da América do Norte houver amadurecido, terá o mundo que colher frutos semelhantes. ${ }^{9}$

No Brasil essas sementes espalhadas por toda a parte germinaram há muito. E se o mundo não colheu os mesmos frutos, nem sabe que estamos colhendo, é porque o Brasil não representa nele papel algum, e está escondido à civilização "pelos últimos restos do escuro nevoeiro que pesa ainda sobre a América". ${ }^{10}$

\footnotetext{
${ }^{9}$ Mommsen, História romana, Livro V, cap. XI.

${ }^{10}$ Antônio Cândido, sessão de 8 de janeiro de 1881, (Câmara dos Deputados de Portugal).
} 